\title{
The role of water-vapour photodissociation on the formation of a deep minimum in mesopause ozone
}

\author{
I. M. Vardavas ${ }^{1}$, J. H. Carver ${ }^{2}$, F. W. Taylor ${ }^{3}$ \\ ${ }^{1}$ Department of Physics, University of Crete, and Foundation for Research and Technology - Hellas, Heraklion, \\ GR-71409, Crete, Greece \\ ${ }^{2}$ Research School of Physical Sciences and Engineering, Institute of Advanced Studies, Australian National University, \\ Canberra, ACT 0200, Australia \\ ${ }^{3}$ Atmospheric, Oceanic and Planetary Physics, University of Oxford, England
}

Received: 7 August 1996 / Revised: 25 July 1997 / Accepted: 31 July 1997

\begin{abstract}
A one-dimensional atmospheric photochemical model with an altitude grid of about $1.5 \mathrm{~km}$ was used to examine the structure of the global mean vertical ozone profile and its night-time-to-daytime variation in the upper atmosphere. Two distinct ozone layers are predicted, separated by a sharp drop in the ozone concentration near the mesopause. This naturally occurring mesopause ozone deep minimum is primarily produced by the rapid increase in the destruction of water vapour, and hence increase in $\mathrm{HO}_{\mathrm{x}}$, at altitudes between 80 and $85 \mathrm{~km}$, a region where water-vapour photodissociation by ultraviolet radiation of the solar Lyman-alpha line is significant, and where the supply of water vapour is maintained by methane oxidation even for very dry conditions at the tropospheric-stratospheric exchange region. The model indicates that the depth of the mesopause ozone minimum is limited by the efficiency with which inactive molecular hydrogen is produced, either by the conversion of atomic hydrogen to molecular hydrogen via one of the reaction channels of $\mathrm{H}$ with $\mathrm{HO}_{2}$, or by Lyman-alpha photodissociation of water vapour via the channel that leads to the production of molecular hydrogen. The ozone concentration rapidly recovers above $85 \mathrm{~km}$ due to the rapid increase in $\mathrm{O}$ produced by the photodissociation of $\mathrm{O}_{2}$ by absorption of ultraviolet solar radiation in the Schumann-Runge bands and continuum. Above $90 \mathrm{~km}$, there is a decrease in ozone due to photolysis as the production of ozone through the three-body recombination of $\mathrm{O}_{2}$ and $\mathrm{O}$ becomes slower with decreasing pressure. The model also predicts two peaks in the night-time/daytime ozone ratio, one near $75 \mathrm{~km}$ and the other near $110 \mathrm{~km}$, plus a strong peak in the night-time/ daytime ratio of $\mathrm{OH}$ near $110 \mathrm{~km}$. Recent observational evidence supports the predictions of the model.
\end{abstract}

Key words Atmospheric composition and structure · Middle atmosphere $\cdot$ Thermosphere .

Transmission and scattering of radiation

\section{Introduction}

We have examined the role of $\mathrm{H}_{2} \mathrm{O}$ photodissociation on ozone concentration in the upper atmosphere with particular emphasis on the region between 70 and $95 \mathrm{~km}$ altitude, where we expect water-vapour photodissociation by the solar Lyman-alpha line to be important. As was shown by Lewis et al. (1983), the photodestruction rate of water vapour by Lyman-alpha peaks within the layer between 70 and $95 \mathrm{~km}$. We have therefore used a $1 \mathrm{D}$ photochemical model with a fine pressure grid (corresponding to intervals of about $1.5 \mathrm{~km}$ at these altitudes) in order to isolate processes that might have small characteristic length scales. Our present study is motivated by the wealth of recent satellite concentration data of atmospheric species important to atmospheric ozone photochemistry that are available from such data bases as UARS/HALOE, ISAMS, MLS, ATMOS and SME with ground-based and in situ data avaliable for validation. In this initial study we compare our model predictions with some typical vertical ozone profiles obtained by ATMOS (Atmospheric Trace Molecule Spectroscopy experiment on Spacelab 3) and HALOE (Halogen Occultation Experiment launched on the Upper-Atmospheric Research Satellite, UARS, in September 1991 as part of the Mission to Planet Earth, MTPE, Program). Figures 1 and 2 show typical vertical ozone profiles obtained by HALOE at sunrise and sunset, respectively. Ozone values with altitude are given in the HALOE data base along with a quality factor which represents the statistical error in the measurements. An estimate of the error, taken here to be the quality divided by four (see Overview of HALOE Data Quality Status in the 
HALOE Ozone Data

2 January 1992, Lat: 28.54, Lon: 235.65, Mode: Rise

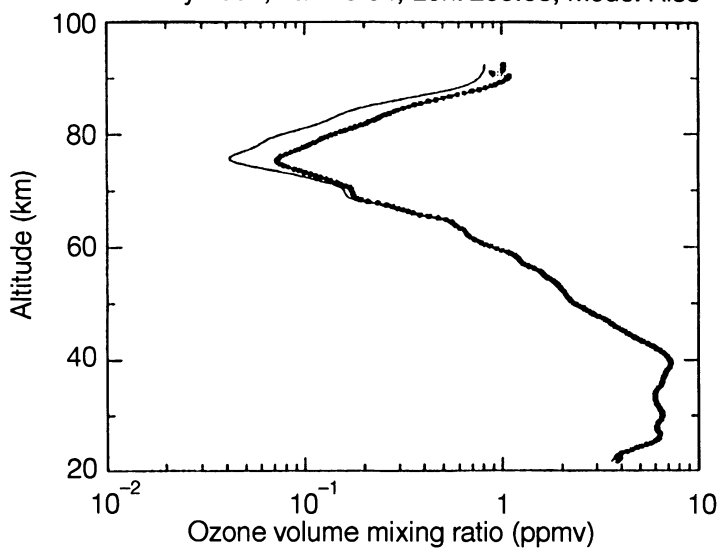

HALOE Ozone Data

6 August 1992, Lat: 28.57, Lon: 176.59, Mode: Rise

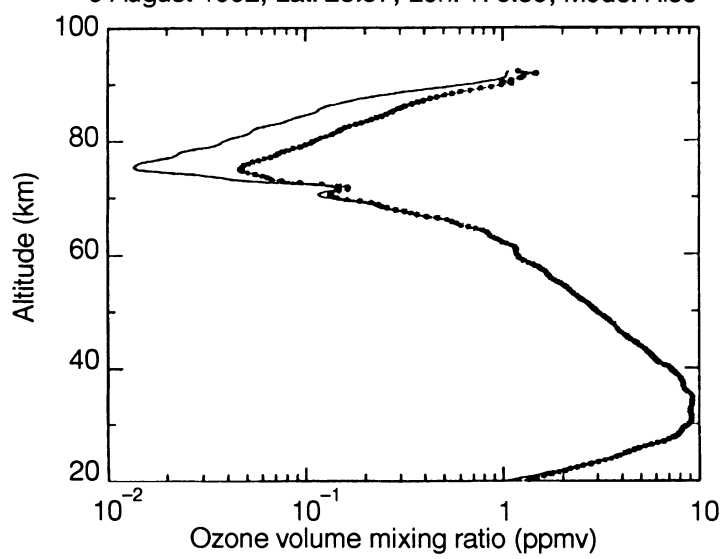

HALOE Ozone Data

27 May 1992, Lat: 28.16, Lon: 59.29, Mode: Rise

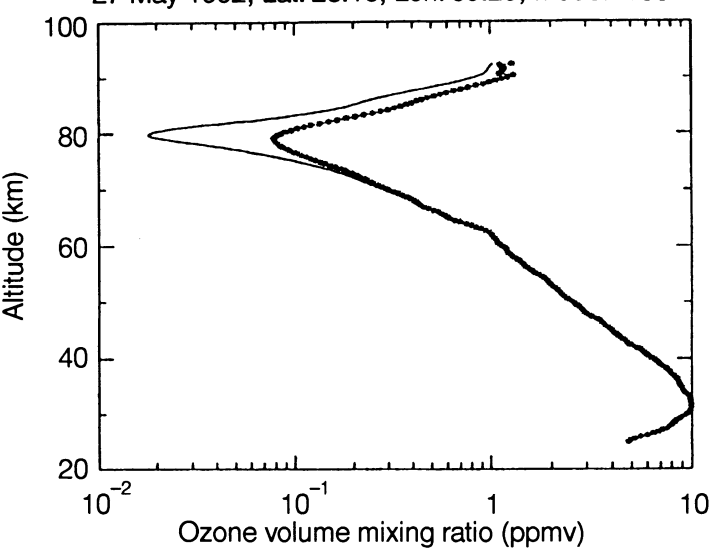

HALOE Ozone Data

18 October 1992, Lat: 28.14, Lon: 298.28, Mode: Rise

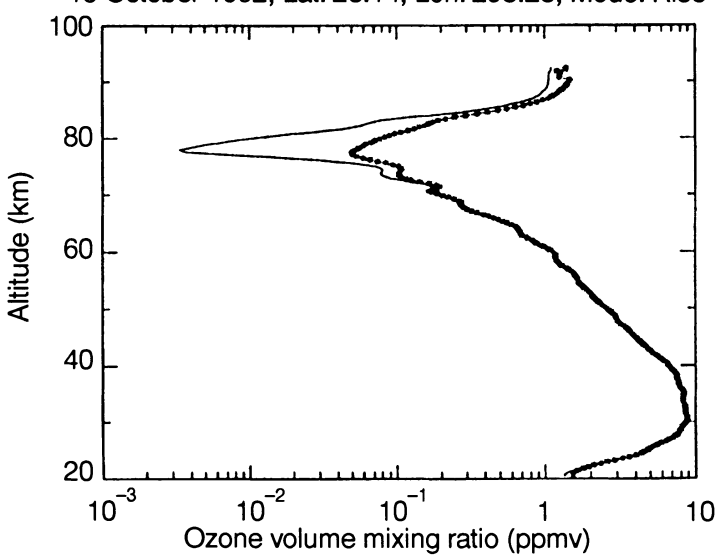

Fig. 1. A sample of HALOE ozone profiles showing mean (fine line) and estimated upper limit (thick line) profiles at sunrise in the northern hemisphere

data base), gives an indication of the upper limit of the measurements when added to the given mean value. Above $70 \mathrm{~km}$, the estimated upper limit starts to deviate from the mean value. However, both the mean profiles and the estimated upper limit profiles indicate that there is a deep minimum generated near the mesopause. The depth of the minimum is variable with minimum mixing ratios usually below $0.1 \mathrm{ppmv}$. Our model computations show that the deep mesopause ozone minimum is created by the reaction of ozone with the active hydrogen species $\mathrm{HO}_{\mathrm{x}}\left(\mathrm{H}, \mathrm{OH}\right.$ and $\left.\mathrm{HO}_{2}\right)$ that are produced by the photodissociation of water vapour, and that the variability of the depth of the minimum depends on the efficiency of the conversion of $\mathrm{H}$ to $\mathrm{H}_{2}$ through the reaction of $\mathrm{H}$ with $\mathrm{HO}_{2}$, and on the production of molecular hydrogen during Lyman-alpha photodissociation of water vapour.

\section{The role of water-vapour photodissociation}

The role of the $\mathrm{HO}_{\mathrm{x}}$ species $\left(\mathrm{H}, \mathrm{OH}\right.$ and $\left.\mathrm{HO}_{2}\right)$ in destroying ozone near the mesopause was investigated in detail by Allen et al. (1984), who stressed the key role played by reactions which convert the active-hydrogen
$\mathrm{HO}_{\mathrm{x}}$ species to the inactive-hydrogen species $\mathrm{H}_{2}$ and $\mathrm{H}_{2} \mathrm{O}$. The subsequent reaction rate measurements of Keyser (1986) for the reaction of $\mathrm{H}$ with $\mathrm{HO}_{2}$ and estimates of the branching ratios which lead to either active or inactive hydrogen species highlighted the role of this reaction in controlling ozone concentrations near the mesopause. The reaction of $\mathrm{H}$ with $\mathrm{HO}_{2}$ has three reaction channels (e.g. Keyser, 1986; DeMore et al., 1994)

$$
\begin{aligned}
& \mathrm{H}+\mathrm{HO}_{2} \rightarrow \mathrm{OH}+\mathrm{OH} \quad 0.90 \pm 0.04, \\
& \mathrm{H}+\mathrm{HO}_{2} \rightarrow \mathrm{O}+\mathrm{H}_{2} \mathrm{O} \quad 0.02 \pm 0.02
\end{aligned}
$$

where the first which leads to the production of the active hydrogen species $\mathrm{OH}$ is dominant (branching ratio 0.9 ). It is the strength of the third channel which limits the role of water-vapour photodissociation in ozone reduction through the conversion of atomic hydrogen to inactive molecular hydrogen. According to Keyser's work, the third channel's branching ratio was determined from knowledge of the total reaction rate and the branching ratios of the first two channels. 
HALOE Ozone Data

31 January 1992, Lat: 28.02, Lon: 351.28, Mode: Set

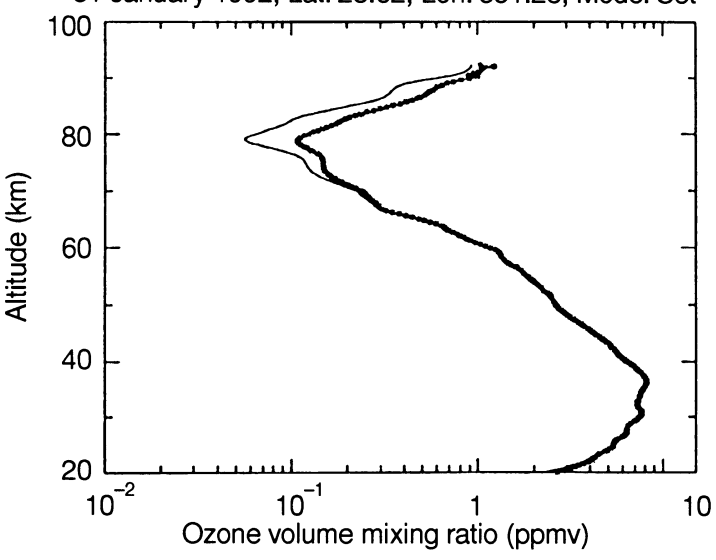

HALOE Ozone Data

19 July 1992, Lat: 27.91 , Lon: 46.22 , Mode: Set

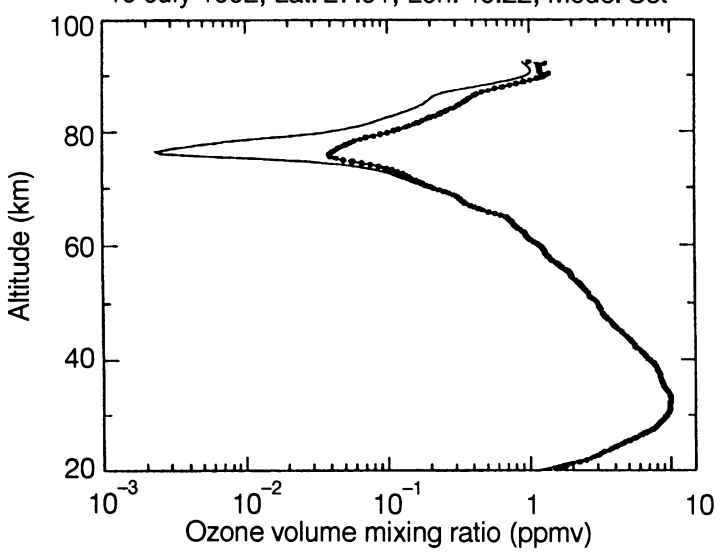

HALOE Ozone Data

9 May 1992, Lat: 28.12, Lon: 264.49, Mode: Set

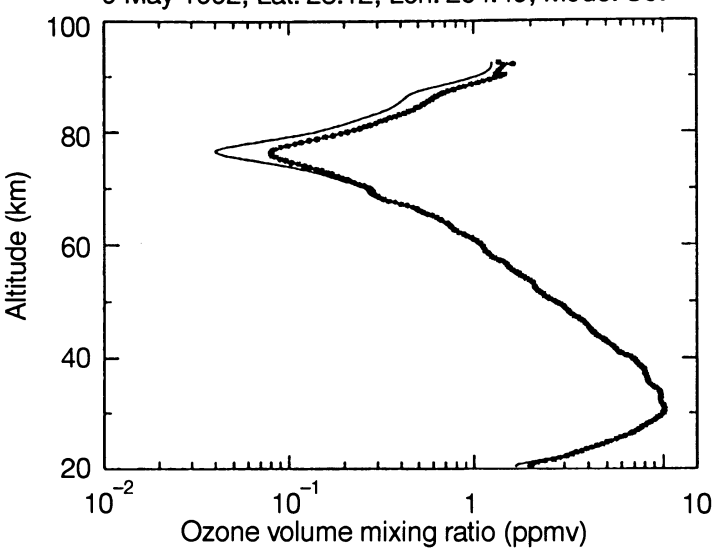

HALOE Ozone Data

17 November 1992, Lat:28.49, Lon:224.63, Mode: Set

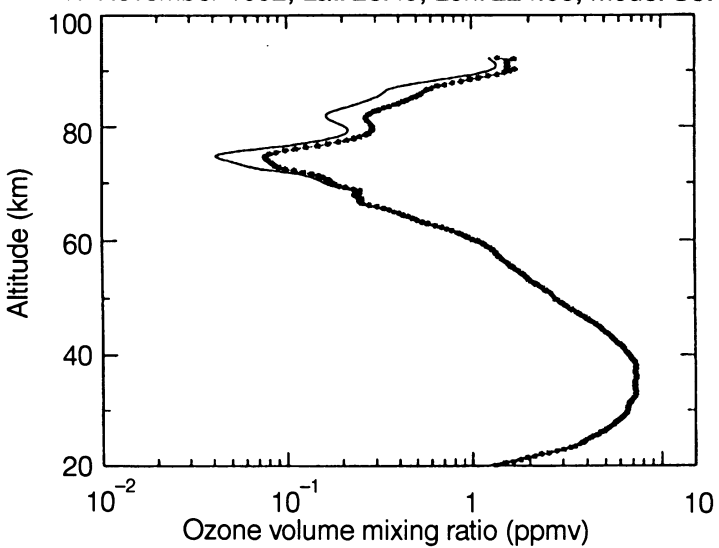

Fig. 2. A sample of HALOE ozone profiles showing mean (fine line) and estimated upper limit (thick line) profiles at sunset in the northern hemisphere

Given the uncertainties in the branching ratios of the first two channels and the fact that these were determined for the temperature range 245-300 K, Keyser concluded that a more exact study of the third channel and its temperature dependence was warranted, having found no significant temperature dependence for the total reaction rate and branching ratios in this temperature range. Clearly, measurements typical of the low-temperature (below $200 \mathrm{~K}$ ) conditions near the mesopause are needed.

Photolysis of water vapour by Lyman-alpha can also result in the production of active and inactive hydrogen species. The two channels for the photodissociation of water vapour by Lyman-alpha are

$\mathrm{H}_{2} \mathrm{O}+\mathrm{h} v \rightarrow \mathrm{H}+\mathrm{OH} \quad \alpha$

$\mathrm{H}_{2} \mathrm{O}+\mathrm{h} v \rightarrow \mathrm{H}_{2}+\mathrm{O}^{1} \mathrm{D} \quad 1-\alpha$,

where the branching ratio $\alpha$ for the first channel is about 0.75 and for the second about 0.25 according to Stief et al. (1972), while according to Banks and Kockarts (1973), the direct production of $\mathrm{H}_{2}$ from the photodissociation of water vapour is a small fraction of the process of Lyman-alpha photodissociation leading to the production of the $\mathrm{HO}_{\mathrm{x}}$ species.

\section{The model}

The 1D photochemical model used comprises two radiation transfer submodels (Vardavas and Carver, 1984a; Strobel, 1987), a radiative-convective equilibrium submodel (Vardavas and Carver, 1985) and a chemical kinetics-diffusion submodel (Vardavas, 1984; Vardavas et al., 1990). One radiation submodel simulates the transfer of solar visible and near-infrared plus terrestrial infrared flux through the atmosphere. These fluxes are used to compute net heating-cooling in the radiativeconvective model which computes the vertical atmospheric temperature profile needed for the computation of reaction rates. Alternatively, one can specify a vertical temperature structure and use the radiative-convective model to compute the radiation fields. The other radiation submodel simulates the atmospheric transfer of solar uv from $0.01 \mu \mathrm{m}$ to Lyman-beta, to take into account reactions of the ionic species leading to the formation of NO in the lower thermosphere (Siskind and Rusch, 1992), and from Lyman-alpha to $0.35 \mu \mathrm{m}$, visible, and near infrared up to $1 \mu \mathrm{m}$ allowing for pure absorption, Rayleigh and cloud Mie multiple scattering and surface reflection (Vardavas and Koutoulaki, 1995). 
The solar flux is used to compute photodissociation rates using 206 wavelength-grid points. The photodissociation rates depend strongly on $\mathrm{O}_{2}$ uv absorption in the highly structured Schumann-Runge (S-R) bands (Lewis et al., 1994; Allen and Frederick, 1982). The $\mathrm{O}_{2}$ $\mathrm{S}-\mathrm{R}$ bands affect both the uv radiation field, and hence the photodissociation rates of other species, and the photodissociation of $\mathrm{O}_{2}$. The incoming solar flux spectrum profile at the top of the atmosphere is normalized to a solar constant of $1367 \mathrm{Wm}^{-2}$. The solar zenith angle, cloud cover, and ground albedo are specified.

Reaction and photodissociation rates (DeMore et al., 1994) are used in a system of 182 reactions, to simulate the vertical transport of 53 species based on a semiempirical expression for vertical eddy diffusion. The diffusion coefficient was taken from Brasseur and Solomon (1984) up to $100 \mathrm{~km}$, while above that the eddy diffusion coefficient was taken to decrease rapidly (e.g. Strobel, 1989; Roble, 1995) and molecular diffusion becomes important. The bi-molecular diffusion coefficients were taken from Vargaftik (1975). Equilibrium vertical profiles of species concentrations were computed using diurnal averaging by computing the daytime and night-time species concentrations (Turco and Whitten, 1978). Near the ground, emission and deposition processes are included (Wuebbles, 1981). Water vapour at the surface and in the troposphere is computed from a specified relative humidity profile and the tropospheric temperature structure.

The model divides the atmosphere into a fine grid of 100 altitude (pressure) levels, to avoid pressure-dependent changes in temperature and composition (Vardavas and Carver, 1984b). Constant-flux boundary conditions are enforced at the top of the atmosphere, and also at the ground for most species rather than fixed concentration boundary conditions, to allow the species concentrations to obtain the values dictated by the photochemical and physical processes. This does not exclude the possibility of specifying a surface flux which can be included through the emission or deposition processes.

The model was used to generate a global mean ozone profile (reflecting mid-latitude conditions) by setting the solar zenith angle to $60^{\circ}$, cloud-cover fraction to 0.5 , surface albedo to 0.1 (mostly ocean), a surface relative humidity of 0.8 and the US Standard Atmosphere temperature structure. The chemistry was set to a 1960 standard without $\mathrm{CFCs}$ and total $\mathrm{Cl}_{\mathrm{x}}$ of $1 \mathrm{ppbv}$ (Johnston et al., 1989).

\section{Results}

\subsection{Diurnally averaged profiles}

In Fig. 3 our model results (curve $a+b+c$ ) for the diurnally averaged ozone profile computed using the $\mathrm{H}+\mathrm{HO}_{2}$ branching ratios of Keyser and a photodissociation branching ratio $\alpha=1$ are compared with the profile of Roble (1995), which used solar minimum

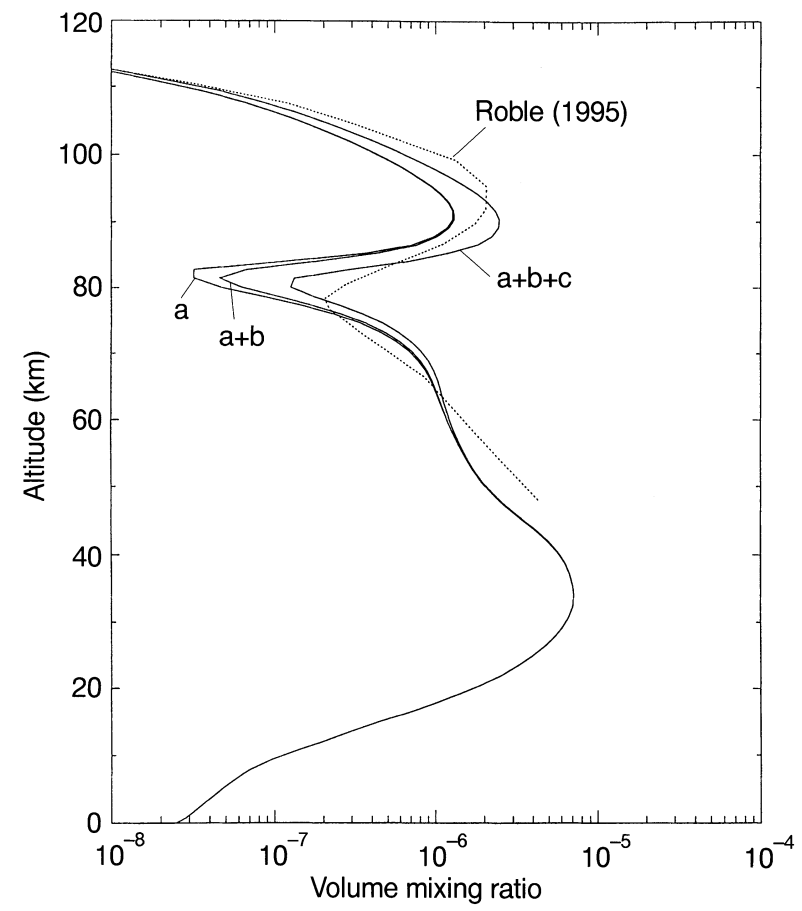

Fig. 3. Model global mean diurnally averaged ozone profiles with and without channels $\mathrm{a}$, $\mathrm{b}$ and $\mathrm{c}$ of the reaction $\mathrm{H}+\mathrm{HO}_{2}$, using a Lymanalpha water-vapour photodissociation branching ratio $\alpha=1$

radiation flux conditions and branching ratios taken from Brasseur and Solomon (1986). Computations with the branching ratios given in Roble showed no significant difference from the ozone profile of curve $\mathrm{a}+\mathrm{b}+\mathrm{c}$. On removing the third channel of the reaction of $\mathrm{H}$ and $\mathrm{HO}_{2}$, the mesopause ozone minimum deepens considerably (curve $a+b$ ), while removal also of the second channel leads to a further deepening of the minimum (curve a). Our model's deep minimum, obtained by removing the channels that convert the active $\mathrm{H}$ species to inactive molecular hydrogen and water vapour, is in better agreement with the observations.

In Fig. 4 are shown the ozone profiles obtained using all three channels for the reaction of $\mathrm{H}$ with $\mathrm{HO}_{2}$ for different values of the Lyman-alpha photodissociation branching ratio $\alpha$. The profile with $\alpha=0$, which corresponds to photodissociation that leads to the production of inactive molecular hydrogen, exhibits a very weak ozone minimum at the mesopause. The profile with $\alpha=1$, which corresponds to photodissociation that leads to the production of active atomic hydrogen, exhibits a deep minimum in ozone concentration at the mesopause. Clearly the reactions that produce molecular hydrogen instead of active atomic hydrogen limit the depth of the ozone minimum at the mesopause.

Our model shows a strong rise in the $\mathrm{H}$ concentration near the mesopause, rising to a value of $1.3 \times 10^{-5}$ ppmv, in keeping with other models (Strobel, 1972; Brasseur and Solomon, 1984) and gives an H escape rate of $2.8 \times 10^{8}$ molecules $/ \mathrm{cm}^{2} \mathrm{~s}$, close to the estimates of others (Carver, 1981; Kasting et al., 1979). Our model $\mathrm{H}_{2} \mathrm{O}$ profile, obtained using a global mean surface 


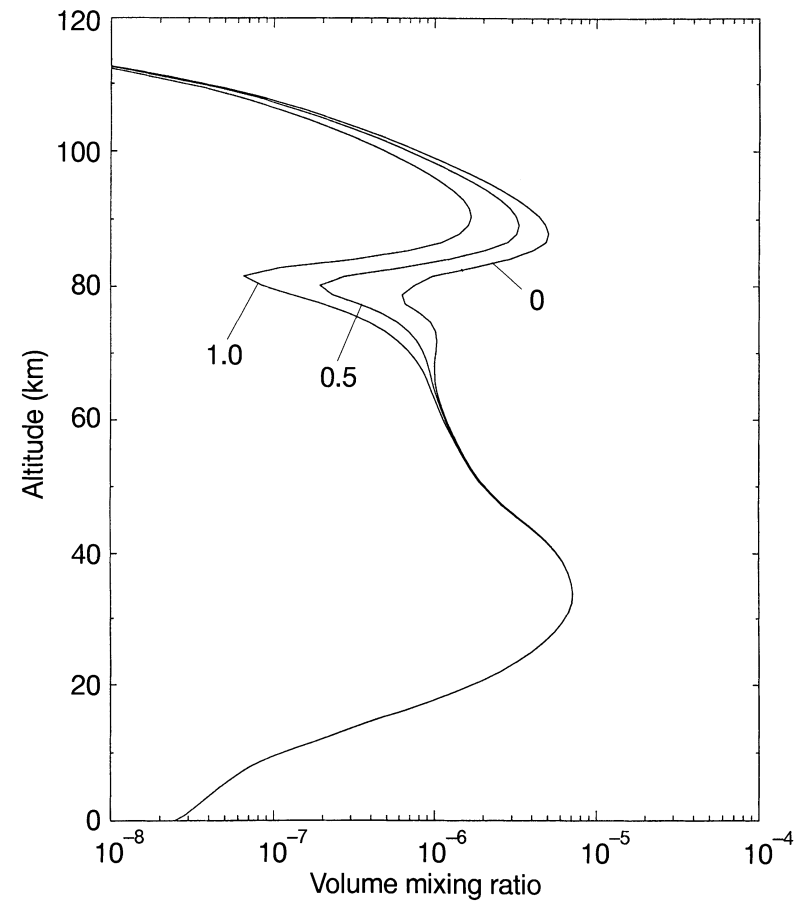

Fig. 4. Model global mean diurnally averaged ozone profiles for different values of the branching ratio $\alpha$ for the photodissociation of water vapour by Lyman-alpha, using the branching ratios of Keyser (1986) for the reaction $\mathrm{H}+\mathrm{HO}_{2}$

relative humidity value of 0.8 , is in very good agreement with the ATMOS observations given in Gunson et al. (1990) and with the UARS/ISAMS observations given in Goss-Custard et al. (1996), as shown in Fig. 5.

Figure 6 shows the ozone profiles obtained for different water-vapour profiles for progressively drier tropopause conditions obtained by setting the surface relative humidity equal to $0.8,0.4$ and 0.1 , using channel a only for the reaction of $\mathrm{H}+\mathrm{HO}_{2}$ and $\alpha=1$. The water vapour mixing ratio in the stratosphere and mesosphere is maintained by methane oxidation even for very dry conditions in the tropospheric-stratospheric exchange region. The corresponding mesopause ozone deep minimum is thus made slightly shallower by the drop in the water-vapour mixing ratio whose peak value in the upper atmosphere goes from 5.7 to $2.9 \mathrm{ppmv}$, when the surface relative humidity is reduced from 0.8 to 0.1 .

\subsection{Night-time/daytime ratios}

In Fig. 7 are given the daytime and night-time model profiles for the channel-a-only case with $\alpha=1$, and these are compared with: the ATMOS sunrise and sunset observations (Gunson et al., 1990) at two locations $48^{\circ} \mathrm{S}$ (sunrise) and $28^{\circ} \mathrm{N}$ (sunset) - from 30 April through 6 May 1985; and with the HALOE observations in May 1992 at $49^{\circ} \mathrm{S}$ (sunrise) and $28^{\circ} \mathrm{N}$ (sunset). Both the sunset and sunrise observations below $80 \mathrm{~km}$ follow more closely the daytime values of the model, while above $80 \mathrm{~km}$ both observation sets exhibit the rapid rise in ozone concentration predicted by the model.

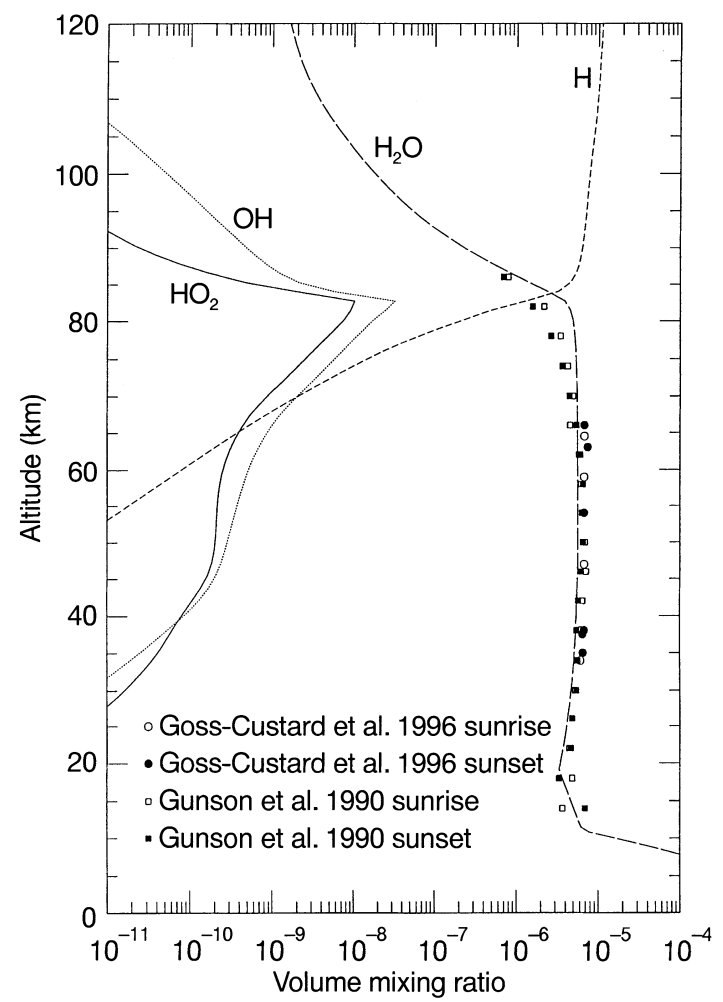

Fig. 5. Model diurnally averaged volume mixing ratio for $\mathrm{HO}_{\mathrm{x}}$ and $\mathrm{H}_{2} \mathrm{O}$ together with sunrise and sunset $\mathrm{H}_{2} \mathrm{O}$ UARS/ISAMS measurements given in Goss-Custard et al. (1996) and the ATMOS measurements given in Gunson et al. (1990)

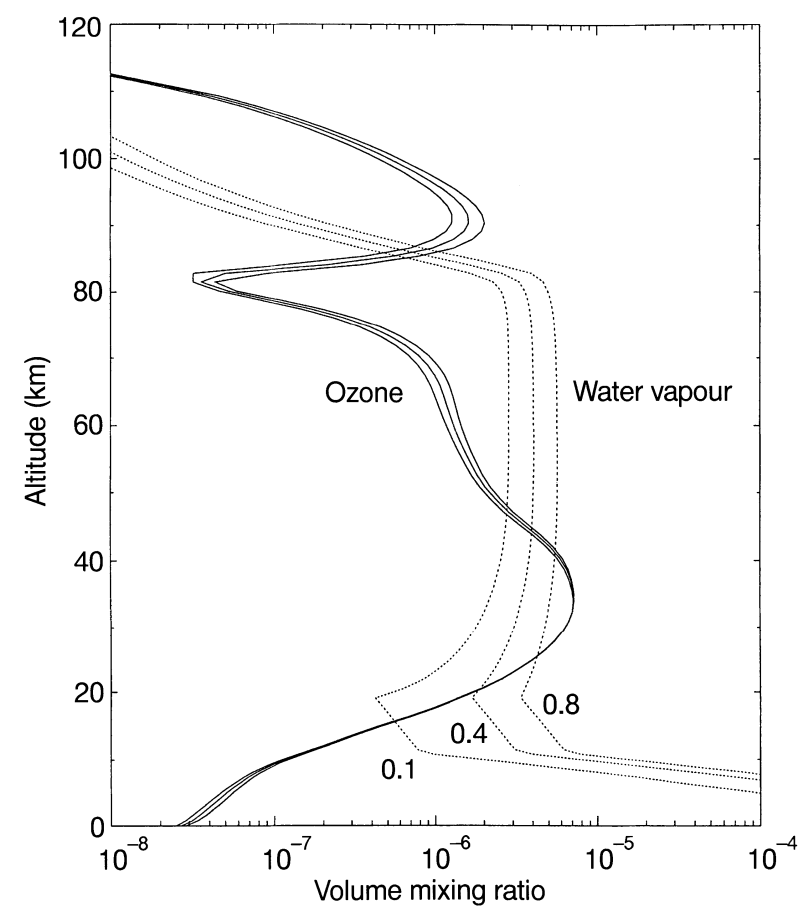

Fig. 6. Model global mean diurnally averaged ozone profiles for different water-vapour profiles computed by setting the surface relative humidity equal to $0.8,0.4$ and 0.1 , using channel a only for the reaction $\mathrm{H}+\mathrm{HO}_{2}$ and $\alpha=1$ 


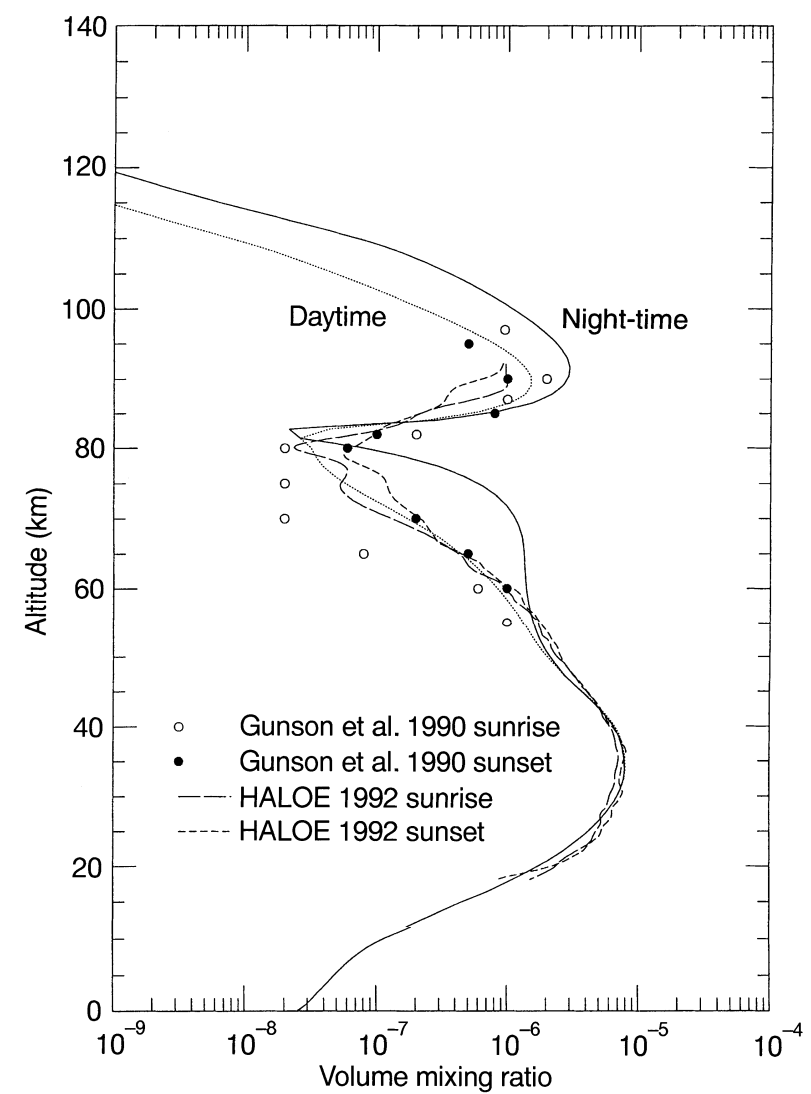

Fig. 7. Global mean daytime and night-time averaged ozone profiles computed by the model are compared with the sunrise and sunset measurements obtained by the ATMOS experiment on Spacelab 3 as given in Gunson et al. (1990) and by UARS/HALOE

The night-time-to-daytime variation of the ozone concentration generated by the model is in agreement with the mid-latitude variation (with a weak seasonal dependence) observed by Connor et al. (1994). The ozone night-time/daytime concentration ratio predicted by the model is given in Fig. 8, along with the corresponding ratios for the $\mathrm{HO}_{\mathrm{x}}$ species and $\mathrm{O}$. The ratio for ozone is in very good agreement with the observations up to $70 \mathrm{~km}$, with the night-time mixing ratio remaining nearly constant at about 1.5 ppmv between 60 and $70 \mathrm{~km}$, also in agreement with the observations. The model predicts two distinct peaks in the ozone night-time/daytime ratio, one near $75 \mathrm{~km}$ and another near $110 \mathrm{~km}$, plus a sharp narrow dip at about $82 \mathrm{~km}$, which corresponds to a region where the nighttime/daytime ratios of $\mathrm{OH}$ and $\mathrm{HO}_{2}$ exhibit very sharp peaks, resulting in more effective night-time destruction of ozone by these two species.

\section{Discussion}

Our interpretation of the strong ozone reduction in the mesopause region and of the night-time/daytime ratios is as follows.

In the stratosphere below about $50 \mathrm{~km}$, the destruction of ozone is balanced by three-body recombination of $\mathrm{O}$ and $\mathrm{O}_{2}$, so that the equilibrium that is rapidly
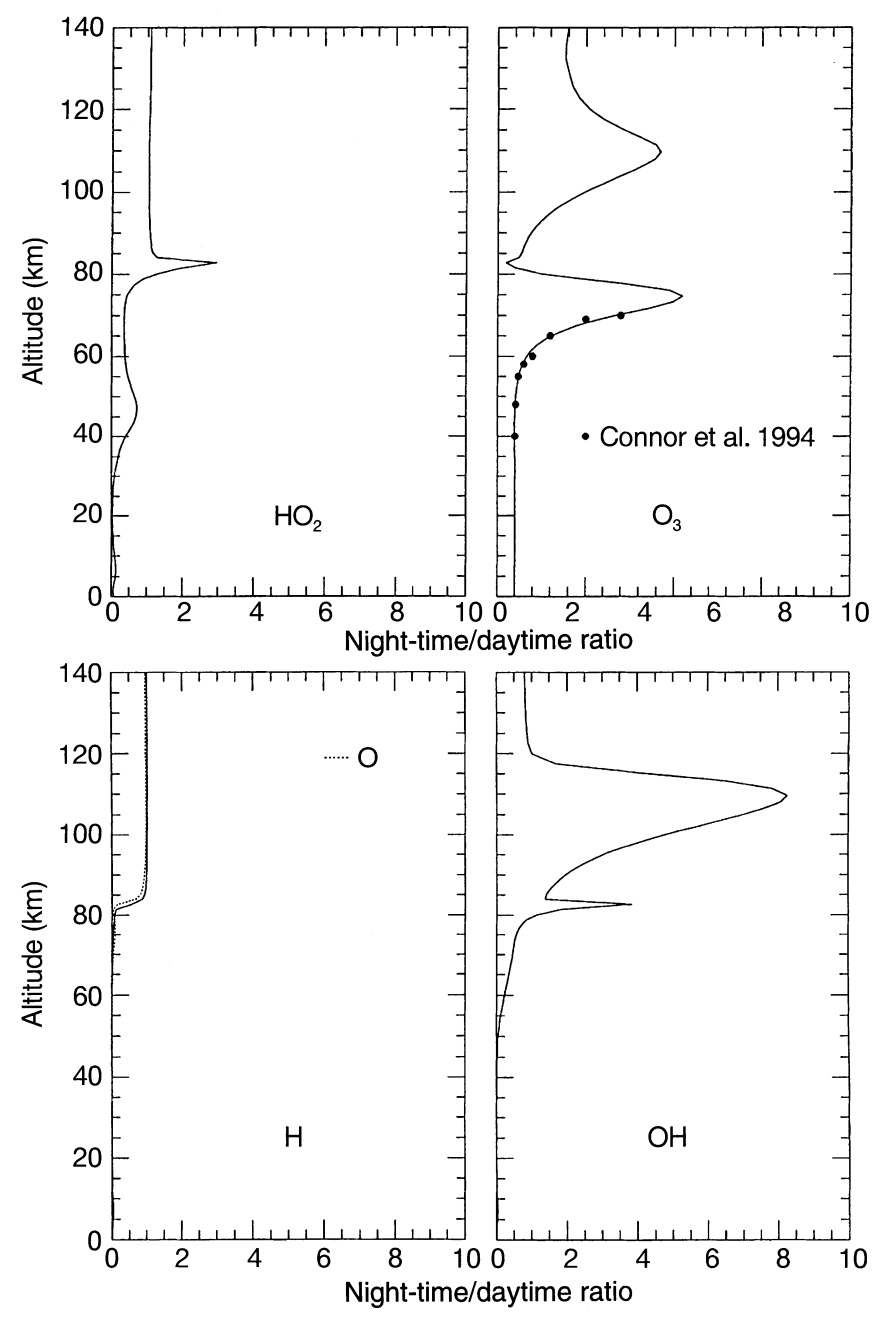

Fig. 8. Model night-time/daytime ratios for the $\mathrm{HO}_{\mathrm{x}}$ species and for $\mathrm{O}_{3}$. Solid circles are the ground-based microwave $\mathrm{O}_{3}$ ratio observations of Connor et al. (1994)

maintained during daytime is unaltered at night-time. Note that the night-time/daytime ratio for $\mathrm{O}$ is negligible up to about $70 \mathrm{~km}$.

Between 50 and $70 \mathrm{~km}$, direct photolysis of ozone in the Hartley-Huggins bands reduces the ozone daytime concentration, while the night-time mixing ratio is maintained fairly constant with altitude (Fig. 7) through (eddy) diffusive equilibrium with the atmospheric layers from below. The result is a rise in the night-time/daytime concentration ratio of ozone as shown in Fig. 8. There is also some rise in the night-time concentration of $\mathrm{HO}_{2}$ due to photodissociation shielding at night-time (Fig. 8). Above $60 \mathrm{~km}$, there is a rapid rise in daytime $\mathrm{H}$ with altitude through the photodissociation of water vapour by Lyman-alpha and ultraviolet radiation in the region of the Schumann-Runge bands of oxygen. This is accompanied by a rise in the daytime concentration of the other $\mathrm{HO}_{\mathrm{x}}$ species, $\mathrm{OH}$ and $\mathrm{HO}_{2}$.

Between 70 and $80 \mathrm{~km}$, there is a rise in night-time $\mathrm{H}$ accompanied by an increase in the other $\mathrm{HO}_{\mathrm{x}}$ species, as diffusion from above rises the $\mathrm{H}$ night-time/daytime ratio towards unity, which occurs at about $85 \mathrm{~km}$. This results in a decrease in the night-time/daytime ratio of 
ozone between 70 and $80 \mathrm{~km}$. The very rapid rise in night-time $\mathrm{H}$ between 80 and $85 \mathrm{~km}$ results in a rapid rise in night-time $\mathrm{OH}$ and $\mathrm{HO}_{2}$, as the latter is shielded at night from photodissociation, with an associated sharp drop in the night-time/daytime ozone ratio below unity. In this region, atomic oxygen rises rapidly due to the photodissociation of molecular oxygen by absorption of solar ultraviolet radiation by the SchumannRunge bands and continuum. As in the case of $\mathrm{H}$, through diffusion from above, the night-time/daytime ratio of $\mathrm{O}$ rapidly rises to unity at about $85 \mathrm{~km}$. This results in two processes.

First, the rapid rise in $\mathrm{O}$ between 80 and $90 \mathrm{~km}$ produces a rapid rise in ozone concentration both during daytime and night-time (Fig. 7), sufficient to counteract the effects of the decreased production of ozone with altitude via the pressure-dependent threebody recombination of $\mathrm{O}$ and $\mathrm{O}_{2}$. Above $90 \mathrm{~km}$, there is a rapid decrease in daytime ozone with altitude due to photolysis, accompanied by a drop in night-time ozone, as the fall in pressure results in a decrease in the rate of ozone production via the three-body recombination of $\mathrm{O}$ and $\mathrm{O}_{2}$.

Photolysis produces a rise in the night-time/daytime ozone ratio, with a peak at about $110 \mathrm{~km}$, as shown in Fig. 8. Secondly, since $\mathrm{HO}_{2}$ in this region is created by three-body recombination of $\mathrm{H}$ and $\mathrm{O}_{2}$ and is destroyed by reaction with $\mathrm{O}$, and both $\mathrm{H}$ and $\mathrm{O}$ have night-time/ daytime ratios of unity above about $85 \mathrm{~km}$, the nighttime/daytime ratio of $\mathrm{HO}_{2}$ also falls to unity. The drop in the night-time/daytime ratio of $\mathrm{HO}_{2}$ initially produces a drop in the ratio of $\mathrm{OH}$, but this is followed by a rise in the night-time/daytime ratio of $\mathrm{OH}$ as ozone reacts with $\mathrm{H}$ to produce $\mathrm{OH}$ in this region. The $\mathrm{OH}$ night-time/ daytime ratio therefore follows the variation in the ozone night-time/daytime ratio.

We have performed some preliminary sensitivity tests to evaluate the response of the ozone deep minimum near the mesopause to changes in some of the atmospheric properties. Reduction of the reaction rate constant for the reaction of $\mathrm{HO}_{2}$ with $\mathrm{O}$ to produce $\mathrm{OH}$ and $\mathrm{O}_{2}$ by $70 \%$ of its JPL94 value (DeMore et al., 1994), as proposed by Clancy et al. (1994), did not change the structure of the minimum and second ozone layer, but did increase the ozone concentration in the layers from 40 to $70 \mathrm{~km}$, in keeping with their results. We have also made a preliminary examination of the effect of the thermospheric rise in temperature on the ozone concentration and night-time/daytime ratio profiles by setting the temperature equal to the minimum mesopause value of $186 \mathrm{~K}$. The effect was to remove the second peak in the ozone night-time/daytime ratio near $110 \mathrm{~km}$ and to replace it by a continuous rise from about $100 \mathrm{~km}$. The thermospheric rise in NO was also found not to affect significantly the structure of the second ozone layer. Variation of the ozone mesopause minimum between solar cycle minimum and maximum [using a uv flux variation from Vardavas (1987)] was found to be weak, although both the stratospheric and lower thermospheric peaks in ozone concentration were found to be enhanced at solar maximum as expected.

\section{Summary}

Our model computations indicate that there are two distinct ozone layers in the atmosphere, separated by a sharp drop in the ozone concentration near the mesopause. The depth of the mesopause ozone minimum is limited by the efficiency with which inactive molecular hydrogen is produced, either by the conversion of atomic hydrogen to molecular hydrogen via one of the reaction channels of $\mathrm{H}$ with $\mathrm{HO}_{2}$ or by Lyman-alpha photodissociation of water vapour via the channel that leads to the production of molecular hydrogen. Recent satellite observations exhibit this deep minimum in mesopause ozone. Both laboratory reaction rates between $\mathrm{H}$ and $\mathrm{HO}_{2}$ at low temperatures and more accurate ozone measurements above $80 \mathrm{~km}$ are required better to quantify the depth of the minimum and its variation.

Acknowledgements. This research project was supported by a NATO Collaborative Research Grant (CRG 940950).

Topical Editor F. Vial thanks two referees for their help in evaluating this paper.

\section{References}

Allen, M., and J. E. Frederick, Effective photodissociation cross sections for molecular oxygen and nitric oxide in the SchumannRunge bands, J. Atmos. Sci., 39, 2066-2075, 1982.

Allen, M., J. I. Lunine, and Y. L. Yung, The vertical distribution of ozone in the mesosphere and lower atmosphere, J. Geophys. Res., 89, 4841-4872, 1984.

Banks, P. M., and G. Kockarts, Aeronomy, Part A, Academic Press, New York, 1973.

Brasseur, G. M., and S. Solomon, Aeronomy of the middle atmosphere, D. Reidel, Norwell, Mass., 1984.

Carver, J. H., Prebiotic atmospheric oxygen levels, Nature, 292, 136-138, 1981.

Clancy, R. T., B. J. Sandor, D. W. Rusch, and D. O. Muhleman, Microwave observations and modeling of $\mathrm{O}_{3}, \mathrm{H}_{2} \mathrm{O}$ and $\mathrm{HO}_{2}$ in the mesosphere, J. Geophys. Res. 99, 5465-5473, 1994.

Connor, B. J., D. E. Siskind, J. J. Tsou, A. Parish, and E. E. Remsberg, Ground-based microwave observations of ozone in the upper stratosphere and mesosphere, J. Geophys. Res., 99, 16757-16770, 1994

DeMore, W. B., S. P. Sander, D. M. Golden, R. F. Hampson, M. J. Kurylo, C. J. Howard, A. R. Ravishankara, C. E. Kolb, and M. J. Molina, Chemical kinetics and photochemical data for use in stratospheric modelling, JPL Publ. 94-20, Pasadena, 1994.

Goss-Custard, M. A., J. J. Remedios, A. Lambert, F. W. Taylor, C. D. Rodgers, M. Lopez-Puertas, G. Zaragoza, M. R. Gunson, M. R. Suttie, J. E. Harries, and J. M. Russell III, Measurements of water vapour distributions by the improved stratospheric and mesospheric sounder: Retrieval and validation, J. Geophys. Res., 101, 9907-9928, 1996.

Gunson, M. R., C. B. Farmer, N. R. Norton, R. Zander, C. P. Rinsland, J. H. Shaw, and B. C. Gao, Measurements of $\mathrm{CH}_{4}$, $\mathrm{N}_{2} \mathrm{O}, \mathrm{CO}, \mathrm{H}_{2} \mathrm{O}$, and $\mathrm{O}_{3}$ in the middle atmosphere by the Atmospheric Trace Molecule Spectroscopy Experiment on Spacelab 3, J. Geophys. Res., 95, 13867-13882, 1990.

Johnston, H. S., D. E. Kinnison, and D. J. Wuebbles, Nitrogen oxides from high-altitude aircraft: an update of potential effects on ozone, J. Geophys. Res., 94, 16351-16363, 1989.

Kasting, J. F., S. C. Liu, and T. M. Donahue, Oxygen levels in the prebiological atmosphere, J. Geophys. Res., 84, 3097-3107, 1979. 
Keyser, L. F., Absolute rate constant and branching fractions for the $\mathrm{H}+\mathrm{HO}_{2}$ reaction from 240-300 K, J. Phys. Chem., 90, 2994-3003, 1986.

Lewis, B. R., I. M. Vardavas, and J. H. Carver, The aeronomic dissociation of water vapor by solar $\mathrm{H}$ Lyman $\alpha$ radiation, $J$. Geophys. Res., 88, 4935-4940, 1983.

Lewis, B. R., S. T. Gibson, and P. M. Dooley, Fine-structure dependence of predissociation linewidth in the SchumannRunge bands of molecular oxygen, J. Chem. Phys., 100, 7012 7035, 1994.

Roble, R. G., Energetics of the mesosphere and thermosphere, in The upper mesosphere and lower thermosphere: a review of experiment and theory, Eds. R. M. Johnson, and T. L. Killeen, Geophysical Monograph 87, AGU, pp. 1-21, 1995.

Siskind, D. E., and D. W. Rusch, Nitric oxide in the middle to upper thermosphere, J. Geophys. Res., 97, 3209-3217, 1992.

Stief, L. J., B. Donn, S. Glicker, E. P. Gentieu, and J. E. Mentall, Photochemistry and lifetimes of interstellar molecules, Astrophys. J., 171, 21-30, 1972.

Strobel, D. F., Minor neutral constituents in the mesosphere and lower thermosphere, Radio Sci., 7, 1-21, 1972.

Strobel, D. F., Radiative heating-cooling and the energetics of the stratosphere and mesosphere, Rev. Geophys., 25, 497-500, 1987.

Strobel, D. F., Constaints on gravity-wave induced diffusion in the middle atmosphere, PAGEOPH, 130, 533-546, 1989.

Turco, R. P., and R. C. Whitten, A note on the diurnal averaging of aeronomical models, J. Atmos. Terr. Phys. 40, 13-20, 1978.
Vardavas, I. M., Modelling reactive gas flows within shock tunnels, Aust. J. Phys., 37, 1-21, 1984.

Vardavas, I. M., Atmospheric temperature response to solar cycle uv flux variations, Solar Phys., 108, 403-410, 1987.

Vardavas, I.M., and J. H. Carver, Solar and terrestrial parameterizations for radiative-convective models, Planet. Space Sci., 32, 1307-1325, 1984a.

Vardavas, I.M., and J. H. Carver, Comments on the NewtonRaphson method for obtaining temperature profiles from radiative-convective models, Planet. Space Sci., 32, 803-807, 1984b.

Vardavas, I. M., and J. H. Carver, Atmospheric temperature response to variations in $\mathrm{CO}_{2}$ concentration and the solarconstant, Planet. Space Sci., 33, 1187-1207, 1985.

Vardavas, I.M., and K. Koutoulaki, A model for the solar radiation budget of the northern hemisphere: Comparison with Earth Radiation Budget Experiment data J. Geophys. Res., 100, 73037314, 1995.

Vardavas, I. M., L. M. Cannon, and K. R. Ryan, BOEING-CSIRO joint research effort, ozone studies project, Tech. Rep. 2, CSIRO Division of Applied Physics, Sydney, Australia, 1990.

Vargaftik, N. B., Tables on the Thermophysical Properties of Liquids and Gases, Wiley, New York, 1975.

Wuebbles, D.J., A summary of the LLNL one-dimensional transport-kinetics model of the troposphere and stratosphere UCID19185, Lawrence Livermore National Laboratory, Livermore, 1981. 